\title{
A DIVERSIDADE DE PRÁTICAS PRODUTIVAS DE FAMÍLIAS AGROEXTRATIVISTAS NA AMAZÔNIA
}

\author{
Alciene Oliveira Felizardo ${ }^{1}$ \\ Carla Giovana Souza Rocha ${ }^{2}$
}

\begin{abstract}
RESUMO
O presente trabalho visa caracterizar as práticas produtivas de famílias agroextrativistas amazônicas, evidenciando o processo de inserção da criação de aves proporcionado pela participação em projeto local. Para isso foram entrevistadas onze famílias das Ilhas do Capim, Caripetuba e Xingu, município de Abaetetuba no Pará. O estudo identificou que as famílias agroextrativistas das Ilhas do Capim, Caripetuba e Xingu são heterogêneas no que se refere à disponibilidade de bases de recursos (sociais e materiais), composição, organização e funcionamento do sistema família-estabelecimento. As famílias agroextrativistas foram enquadradas em três tipos: tipo I, com base restrita de recurso material com predominância de renda externa, tipo II, com base de recurso material com média diversidade e renda centrada no extrativismo do açaí, peixe e camarão e, tipo III, com base de recurso material com alta diversidade e múltiplas fontes de renda. Isso revela que as famílias agroextrativistas beneficiárias do projeto local desenvolvem práticas distintas orientadas pelas particularidades do sistema famíliaestabelecimento que implicam na permanência ou resistência diante de projetos desenvolvimento agrícola padronizados.
\end{abstract}

Palavras-chave: Agroecossistemas familiares. Sistema de produção. Agroextrativismo. Práticas produtivas.

\begin{abstract}
The present work aims to characterize the productive practices of Amazonian agroextractive families, evidencing the process of insertion of bird breeding provided by participation in a local project. For that, eleven families from the Capim, Caripetuba and Xingu Islands, Abaetetuba municipality in Pará, were interviewed. The study identified that the agroextractive families from the Capim, Caripetuba and Xingu Islands are heterogeneous with regard to the availability of resource bases (social and materials), composition, organization and functioning of the family-establishment system. Agroextractive families were classified into three types a) type I: restricted base of material resources with predominance of external income; type II: material resource base with medium diversity and income centered on the extraction of açaí, fish and shrimp; and, type III: material resource base with high diversity and multiple sources of income. This reveals that the agroextractive families that benefit from the local project develop different practices guided by the particularities of the familyestablishment system that imply permanence or resistance in the face of standardized agricultural development projects.
\end{abstract}

Keywords: Family agroecosystems. Production system. Agroextractivism. productive practices.

Data de submissão: 31.08 .2020

Data de aprovação: 20.10 .2020

\footnotetext{
${ }^{1}$ Mestra em Agriculturas Familiares e Desenvolvimento Sustentável pela Universidade Federal do Pará (UFPA). Doutoranda no Programa de Pós-graduação Interdisciplinar em Ciências Humanas da Universidade Federal de Santa Catarina (UFSC). ORCID: https://orcid.org/0000-0002-8476-6649.E-mail: alcifelizardo@yahoo.com.br. ${ }^{2}$ Doutora em Desenvolvimento Rural pela Universidade Federal do Rio Grande do Sul (UFRGS). Professora da Faculdade de Etnodiversidade da Universidade Federal do Pará (UFPA), Campus de Altamira. ORCID:https://orcid.org/0000-0002-7066-0480. E-mail: crocha@ufpa.br.
} 


\section{INTRODUÇÃO}

O agroextrativismo é uma das expressões do campesinato amazônico (GODOI; MENEZES; MARIN, 2009). Para estas autoras, o camponês possui uma característica marcante, a diversidade historicamente construída por meio de formas distintas de apropriação e uso da terra e de outros recursos naturais. Os camponeses apresentam "indissociabilidade entre a unidade de produção e a unidade de consumo, pois tanto uma como a outra fazem apelo aos mesmos membros da família e estão regidas pelos mesmos padrões de autoridade doméstica" (GARCIA JÚNIOR; HEREDIA, 2009, p. 223).

Os camponeses agroextrativistas manejam recursos naturais em três microbiomas amazônicos: a várzea, a terra firme e o mar (CRUZ, 2007). Os igapós, os aningais, os igarapés e as lagoas e lagos formam um ambiente diversificado favorável à vida, onde são mantidas interações biológicas e atuam mecanismos que proporcionam equilíbrio desses ecossistemas, como o caso das inundações provocadas pelos rios (FALESI; SILVA, 1999). Além desses aspectos, fatores como o espaço físico, as condições, habilidades do agricultor e tecnologias influenciam na transformação do meio (REIJNTJES; HAVERKORT; WATERS-BAYER, 1999).

Na Amazônia há uma diversidade de lógicas de reprodução social que, diferente das lógicas agroindustriais reguladas por processos mercadológicos, estão ligadas a formas familiares de reprodução socioambiental ${ }^{3}$ no campo (HURTIENNE, 1999). Estas lógicas são marcadas por processos de autonomia e sustentabilidade que são obtidos em contextos diversos, principalmente no caso da heterogeneidade presente em realidades amazônicas (HURTIENNE, 1999) marcadas pela forte presença do extrativismo.

Como afirma Carvalho e Silva (2015), o extrativismo é, em grande parte, responsável por garantir a reprodução social das famílias, por meio tanto da comercialização quanto do consumo. Essas realidades agroextrativistas possuem uma natureza multifacetada, o que exige uma análise metodologicamente adequada, inclusive para condução e avaliação dos impactos e eficiência de projetos agrícolas de desenvolvimento nos sistemas de produção agroextrativistas amazônicos, que muitas vezes seguem um modelo homogeneizador e programático. Por isso, é importante o uso de abordagens como a sistêmica, em função da crescente complexidade de sistemas organizados e manejados pelo ser humano (PINHEIRO, 2000).

Ao desenvolverem projetos de desenvolvimento agrícola muitas instituições privadas, órgãos públicos, Organizações Não Governamentais (ONGs) etc. consideram os agroextrativistas enquanto grupo homogêneos, assim, propõem projetos padronizados e ignoram a diversidade de estratégias produtivas e as particularidades da constituição dos sistemas família-estabelecimento (FELIZARDO; ROCHA, 2019). Para Niederle (2007), a diversidade de estratégias utilizadas pelos camponeses em seus estabelecimentos, resulta da combinação de diferentes lógicas sociais e produtivas. Essas estratégias são resultantes de processos de trabalho, investimento em capital, ciclo produtivo e reprodução do grupo familiar. A heterogeneidade implica em respostas diferenciadas mesmo diante de circunstâncias estruturais que aparentemente possam apresentar-se enquanto homogêneas (LONG; PLOEG, 2011). Portanto, mesmo diante intervenções por projetos padronizados, as famílias podem desenvolver práticas distintas com variações de acordo com suas estratégias particulares. Diante disso, o presente trabalho visa analisar as práticas produtivas de famílias agroextrativistas para verificar suas respostas diante de intervenções por projetos de desenvolvimento agrícola.

\footnotetext{
${ }^{3}$ A reprodução socioambiental é aquela que resulta da "capacidade das populações rurais de ajustar seus meios de vida aos ecossistemas em que vivem e produzem” (PETERSEN; DAL SOGLIO; CAPORAL, 2009, p.86).
} 


\section{METODOLOGIA}

A pesquisa foi realizada no município de Abaetetuba (Estado do Pará) em novembro de 2017 no âmbito da dissertação de mestrado da primeira autora. Foram entrevistadas 11 famílias em três ilhas distintas: Ilha do Capim, Caripetuba e Xingu. As famílias foram selecionadas em função de serem beneficiárias do Projeto Produzindo a Inclusão implementado pela Associação dos Moradores das Ilhas de Abaetetuba (AMIA). Este projeto foi financiado pelo Banco da Amazônia em 2012 e visou, dentre outras ações, a inserção de criação de frango de granja nos estabelecimentos familiares agroextrativistas.

As informações coletadas visaram a caracterização geral dos sistemas de produção agroextrativistas locais e o aprofundamento sobre as práticas desenvolvidas no sistema de criação. O questionário e o roteiro foram as principais ferramentas utilizadas atrelados à técnica de observação participante (MARCONI; LAKATOS, 1996; FLICK, 2004). Para isso foram acessadas informações referentes a trajetória da família, constituição dos sistemas produtivos, estrutura e o funcionamento do sistema família-estabelecimento e posteriormente realizou-se um aprofundamento do sistema de criação para detalhar as práticas. As entrevistas identificaram aspectos como: composição familiar, ocupação dos membros, composição e estrutura dos subsistemas, tamanho das áreas, acesso à terra e aos demais recursos naturais, produção e renda, finalidades dos produtos e de cada subsistema, conhecimentos adquiridos, acesso às informações, aos serviços públicos, aos mercados e ao crédito, uso e disponibilidade de mão-de-obra ao longo do ano.

O tratamento dessas informações consistiu na criação de tipologia em que a homogeneização das famílias agroextrativistas foi orientada pelas similaridades referentes às características ambientais, sociais e produtivas dos estabelecimentos. Foram definidas categorias ou tipos de sistemas de produção baseado em Garcia Filho (1999). A tipologia foi utilizada para analisar a diversidade de estratégias produtivas dos agroextrativistas. Diante disso, foram caracterizadas as peculiaridades desses sistemas de produção, detalhando os subsistemas que o compõem.

Posteriormente analisou-se as práticas ligadas ao subsistema de criação que recebeu o projeto implementado pela AMIA para compreender como as criações de frango advindas do projeto de desenvolvimento agrícola foram implementadas e/ou adaptadas pelas famílias. Além disso, buscou-se também dados sobre a estrutura e funcionamento dos sistemas de produção agroextrativista, buscando identificar adaptações e/ou mudanças que foram feitas no processo de execução e verificar o que permanece atualmente no sistema.

O estudo das práticas no sistema de criação foi realizado a partir de duas entradas complementares propostas por Landais: a modalidade e a oportunidade (LANDAIS, 1987 apud LANDAIS; DEFFONTAINES, 1988). A modalidade, busca fundamentalmente caracterizar as práticas, tendo esta entrada um aspecto mais descritivo e a oportunidade centra-se na família (subsistema de decisão), visando identificar o que condiciona o agricultor a realizar as práticas adotadas em seus sistemas de criação. Essas possibilidades de análise permitiram o detalhamento das práticas desenvolvidas pelas famílias. Realizou-se ainda, uma síntese do funcionamento do subsistema de criação através da modelização de fluxos. Esse aprofundamento das práticas foi realizado para mostrar a diversidade de estratégias desenvolvidas pelas famílias agroextrativistas.

Foram utilizados os aportes teórico-analíticos da abordagem sistêmica por permitirem analisar os estabelecimentos familiares desde os níveis mais restritos, como as práticas, até níveis mais abrangentes, como as estratégias produtivas. Essas estratégias serão entendidas neste trabalho como ações particulares que abrangem a organização e o funcionamento do 
sistema de produção que visam atender aos objetivos do centro de decisão. Assim, considerase que o sistema de produção agroextrativista está inserido em um sistema famíliaestabelecimento regulado pelo centro de decisão e que não se trata de uma parte isolada, mas de um conjunto de elementos em interação (MAZOYER, 1985 apud BROSSIER, 1987).

\section{RESULTADOS E DISCUSSÃO}

Nas Ilhas do Capim, Caripetuba e Xingu (Abaetetuba, Pará) foram identificados um conjunto de particularidades nos sistemas família-estabelecimentos. Essa diversidade se expressa nas estratégias produtivas, situadas no nível da reprodução material (RAYNAUT, 1994), adotadas pelas famílias entrevistadas $(n=11)$. Trata-se de sistemas compostos por centros de decisão que interrelacionam os subsistemas (extrativista, cultivo, criação, processamento e atividades anexas) e diferentes formas, de acordo com suas estratégias específicas.

Os sistemas família-estabelecimento possuem diferenças em suas bases de recursos material e social (PLOEG, 2008). Para este autor, a base de recurso material refere-se ao conjunto de bens disponíveis em cada estabelecimento (terra, animais, plantas, entre outros) e a base de recursos social refere-se ao conhecimento e à eficiência técnica do trabalho. Conforme Ploeg (2008) o fortalecimento continuado da base de recurso representa a principal estratégia de construção da autonomia das famílias. Os sistema família-estabelecimento, embora apresentem similaridades entre si, possuem especificidades internas, o que permitiu homogeneizá-los em três tipos distintos, como descritos a seguir:

Tipo I: Agroextrativistas ( $n=3$, Capim, Caripetuba e Xingu) com base de recurso material restrita e com predominância de renda externa. Estas famílias do tipo I $(n=3)$ desenvolvem atividades agrícolas e não agrícolas. Tratam-se de famílias que possuem membros que são funcionários públicos e profissionais autônomos que possuem pequenas extensões de terra. Portanto, os centros de decisão realizam atividades promotoras de renda não monetária como sua principal estratégia de trabalho no estabelecimento.

Tipo II: Agroextrativistas ( $\mathrm{n}=7$, Capim, Caripetuba e Xingu) com base de recurso material com média diversidade e renda centrada no extrativismo do açaí, peixe e camarão. Estas famílias possuem base de recursos material maior que as famílias do tipo I e fonte de renda centrada no subsistema extrativista. Diferente das famílias do tipo I, as famílias do tipo II possuem seu próprio estabelecimento (subsistema extrativista) como fonte principal de renda (monetária e não monetária).

Tipo III: Agroextrativistas ( $\mathrm{n}=1$, Xingu) com base de recurso material com alta diversidade e múltiplas fontes de renda. $O$ grupo doméstico incluído neste tipo $(n=1)$ desenvolve, além das atividades agrícolas, algumas não agrícolas. Trata-se de uma família que possui membros que são funcionários públicos, profissionais autônomos e que possui extensão de área de terra bem acima da média. Além destes aspectos, a alta densidade conectiva entre os subsistemas é um elemento contrastante dentre os demais tipos que tem influenciado no aumento contínuo de sinergias internas no estabelecimento e na diversidade de atividades produtivas promotoras de recursos monetários e não monetários.

A base de recurso material pode ser mobilizada por circuitos mercantilizados (venda de excedentes) e não mercantilizados (autoconsumo). Ocorre também a possibilidade de existência de estoque nos estabelecimentos. Esses estoques são recursos endógenos não mobilizados pelo sistema família-estabelecimento (PETERSEN et al., 2017). Trata-se de recursos que representam potenciais intrínsecos aos sistemas e que podem ser mobilizados para atender as necessidades estabelecidas pelo centro de decisão.

Os tipos I, II e III identificados mostram as particularidades das bases de recursos (sociais e materiais) das famílias agroextrativistas e revelam a heterogeneidade dos sistemas 
família-estabelecimento das Ilhas do Capim, Caripetuba e Xingu. Para compreender as respostas diferenciais diante das intervenções advindas de projetos de desenvolvimento agrícola fez-se necessário o detalhamento das práticas produtivas desenvolvidas pelas famílias agroextrativistas que acessaram o projeto de criação de frango.

\subsection{AS PRÁTICAS PRODUTIVAS DE FAMÍLIAS AGROEXTRATIVISTAS NA CRIAÇÃO DE FRANGO DE GRANJA}

Nesta seção apresentam-se as práticas de uma família representante de cada tipo (I, II e III) identificado anteriormente.

\subsubsection{PRÁTICAS PRODUTIVAS EM ESTABELECIMENTO COM BASE RESTRITA DE RECURSO MATERIAL E PREDOMINÂNCIA DE RENDA EXTERNA}

A família representativa deste tipo era constituída por 2 membros em 2012, ano que foi executado o projeto. O casal possui uma área pequena, situada na Ilha Caripetuba, equivalente ao "quintal da casa" com a presença somente de área de várzea. O recurso financeiro responsável pela manutenção da família advém prioritariamente do serviço público, do conserto de motores, ambos realizados pelo marido, e da "debulha do açaí", realizada pela esposa. Esta última é realizada em estabelecimentos familiares próximos a residência do casal, quando necessitam de renda extra para fins específicos, como a compra de materiais de higiene pessoal. Essa organização interna possibilita ao casal e sua filha, a garantia das necessidades para sua reprodução social. A família obteve acesso a 40 frangos que foram criados em um primeiro momento de forma extensiva (solto) no "quintal da casa" e em um segundo momento foi criado de forma intensiva (preso) em um galinheiro em outro estabelecimento.

A família tinha disponibilidade restrita de trabalho no momento do acesso ao projeto de criação de frango, mesmo assim, a criação destes animais não interferiu nas demais atividades já realizadas no estabelecimento. Isso ocorreu devido a esposa, principal membro responsável pelo manejo das aves, não possuir trabalho fixo fora do estabelecimento e ter disponibilidade de dedicação ao manejo dos animais. A alimentação era fornecida duas vezes ao dia, pela manhã e no final da tarde. Quando havia trabalho de "debulha de açaí" a esposa acordava cedo para, antes de sair para os açaizais, realizar o manejo das aves.

A experiência de criação nesta família do tipo I caracterizou-se pelo choque entre as práticas de criação voltadas para a convivência com o ecossistema e práticas de redução de limitações ambientais impostas pelo "Projeto Produzindo a Inclusão", conforme Petersen et al. (2017). Isso pode ser verificado pelos seguintes fatores: a seleção de aves com baixa rusticidade (frango de granja); a infraestrutura artificializadora do ambiente exigida para o desempenho produtivo satisfatório das aves; e, a necessidade de ração balanceada.

A seleção do frango de granja resultou na dificuldade de garantir as condições ambientais favoráveis à criação, devido sua baixa rusticidade. As consequências disso podem ser verificadas no depoimento da agroextrativista:

\footnotetext{
Essa [galinha] de granja é muito melindrosa. Qualquer coisa elas estão morrendo, a comum é melhor porque pode criar solto. Eu perdi nessa época 3, morreu de repente, não sei se foi cobra na época. Amanheceu os 3 no mesmo lugar, não sei, até hoje nunca descobri. Já estavam grandão, foi uma pena, nem pode aproveitar porque a gente não sabia porque foi que morreu (E. C., Ilha Caripetuba, 2017).
}

A baixa rusticidade das aves (muito melindrosa) implicou em sua dificuldade de sobreviver ao ambiente de várzea. Isso resultou em prejuízos, visto que a família nem pode 
aproveitar os animais que morreram. O projeto não deu alternativas de selecionar animais mais adaptados ao ambiente de várzea. Como pode ser percebido no depoimento, a responsável pela criação reconhece que: "a [galinha] comum é melhor porque pode criar solto". Isso mostra que as práticas de redução de limitações ambientais (criar preso) definidas pelo projeto, contrastam com as práticas locais de criação baseadas na convivência com o ecossistema (criar solto).

A imposição da prática de redução de limitações ambientais (criar preso) exigiu a necessidade de construir infraestrutura artificializadora do ambiente para que o desempenho produtivo das aves fosse satisfatório. No caso dessa família, o projeto requereu a construção de galinheiros suspensos para evitar o contato das aves com a água das marés. Estes galinheiros deviam ser uma contrapartida da família para acessar o projeto. A família do tipo I não conseguiu construir a instalação para a recepção das aves em função do recurso financeiro limitado e inexistência de instalações já construídas que pudessem abrigar os animais. Segundo a agroextrativista:

Foi uma experiência boa e ao mesmo tempo ruim, né? Porque eu não consegui fazer na época o galinheiro. Estava sem dinheiro, aí tive que criar solto. Aí, apesar da gente morar perto um do outro, começou a dar problema. Começaram a ir na casa do vizinho e fazer suas necessidades por lá. Eu não tive muito tempo, eu tive logo que eliminar. Não pude ficar muito tempo, em função de não ter tido condições de fazer o galinheiro, como eles orientaram. Mas foi assim mais ou menos, a gente foi chamado lá que tinha sido contemplado, aí eu peguei na época os franguinhos (E. C., Ilha Caripetuba, 2017).

As exigências de infraestrutura do projeto contrastaram com as condições econômicas da família e com as práticas de criação em convivência com o ecossistema (criação solta), conhecida pelo grupo doméstico.

As condições ambientais da várzea e a limitação de área para a construção do galinheiro impossibilitou com que a criação das aves continuasse sendo realizada no "quintal da casa". Para solucionar esse problema a esposa levou os animais para o estabelecimento familiar de sua mãe, onde foi construído um galinheiro que permitiu finalizar a criação. Nesta segunda fase da criação a família sentiu dificuldades de implementar outras práticas de redução de limitações ambientais orientadas pelo projeto.

A primeira foi a dificuldade de atender a necessidade de luz orientada como prática de manejo. Isso ocorreu porque a família, assim como todas as demais estudadas, não possui energia elétrica, por isso utilizam motores de luz que funcionam a óleo diesel. Para evitar esse custo com combustível, a família optou por utilizar a luz de LED ligada a uma bateria de carro. Este tipo de iluminação foi também necessário para dificultar o ataque de morcegos. Além disso, o projeto orientava a prática de manter o chão do galinheiro com maravalha (resto de serragem de madeira) para garantir a temperatura e a coleta das fezes. Todas estas práticas exigidas pelo projeto aumentaram o custo de produção devido à dificuldade de obter localmente os recursos necessários. Isso mostra a incoerência entre a endogeneidade das práticas agroextrativistas e as práticas exógenas propostas pelo projeto local.

As práticas orientadas pela AMIA para a criação das aves exigiram a forte dependência de recursos ligados a matriz agroindustrial da agricultura. $\mathrm{O}$ projeto orientava a alimentação das aves com ração balanceada. Esta ração era doada pela AMIA para atender as necessidades alimentares das aves durante um ciclo de produção completo, constituído de três fases (cria, recria e engorda). Como a criação foi de forma extensiva nas primeiras semanas de criação, os animais demoraram de 3 a 4 meses para atingir o peso ideal para a comercialização. 
Isso fez com que esgotasse a quantidade de ração fornecida pelo projeto ${ }^{4}$, fazendo com que a família necessitasse de outras fontes alimentares. Para isso, a família passou a fornecer o milho quebrado e o milho inteiro para as aves. A aquisição do milho quebrado e do milho inteiro foi uma forma de reduzir ao máximo o custo de produção até que as aves pudessem ser vendidas. Porém, os animais não expressaram bom desempenho produtivo em função dos repertórios técnicos padronizados (PETERSEN, 2011) não terem sido implementados pela família. O fluxograma a seguir (Figura 1) demonstra de forma sintética o funcionamento resultante da implantação das práticas propostas pelo projeto descritas acima.

Figura 1 - Modelização do funcionamento do estabelecimento (tipo I) a partir da introdução da criação de frango.

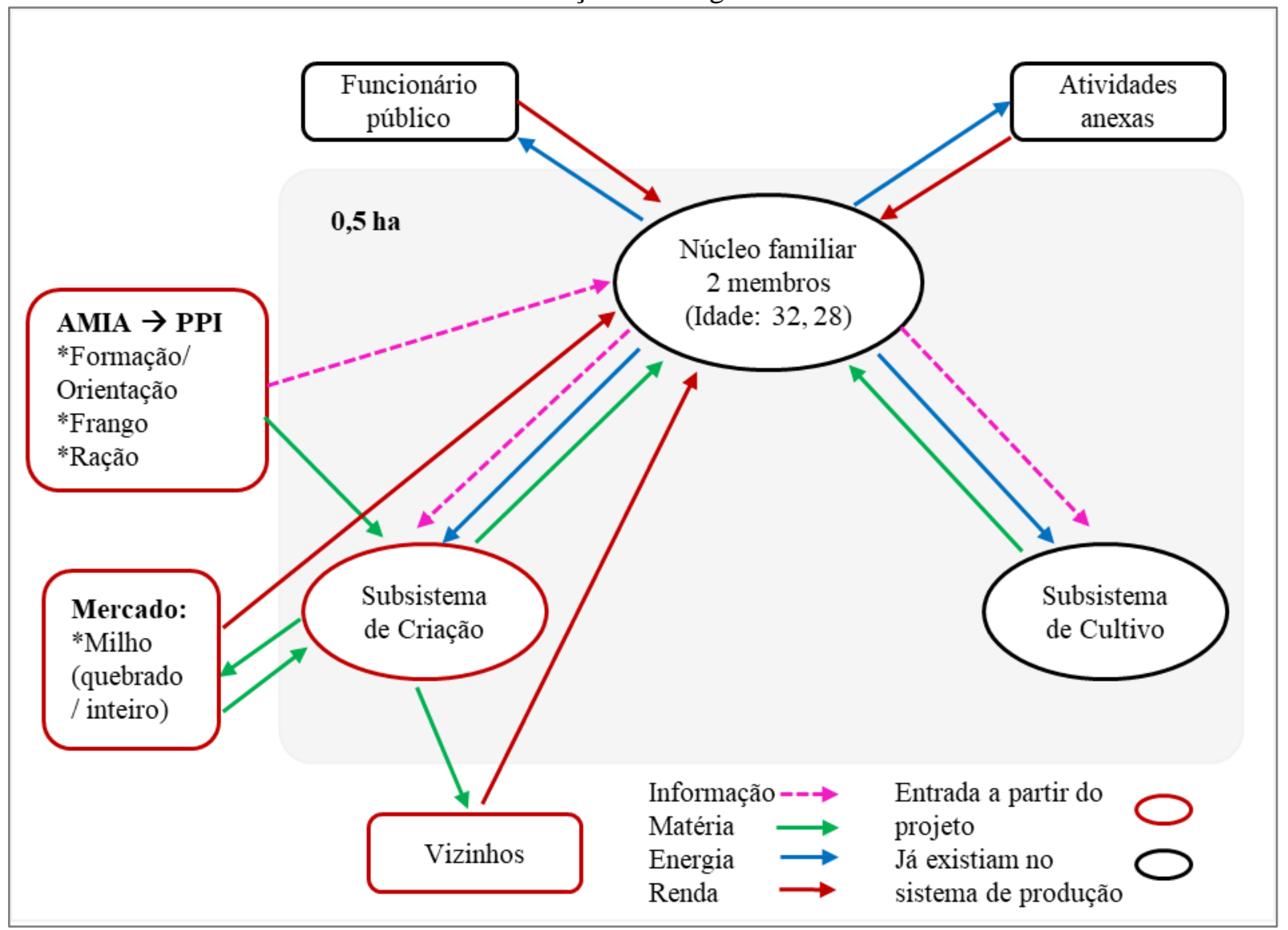

Fonte: Elaborado pelas autoras (2018).

A experiência não avançou para novos ciclos como previsto pelo projeto. Em função das dificuldades encontradas, a família não deu continuidade à atividade de criação. Diante dessa realidade verifica-se que o frango de granja possui restrições em relação ao ambiente de várzea, dominante no estabelecimento analisado. Por serem mais frágeis que os tradicionais criados "soltos" pela maioria das famílias, exigem alto controle de ambiente e alimentação. Esse processo exige custos produtivos que impõem dependência das famílias em relação a recursos tecnológicas não disponíveis em seus estabelecimentos. Além disso, as restrições de área e as condições climáticas (elevada umidade do solo) impõem elevados riscos para a criação de animais com baixa rusticidade, como os frangos de granja. Como descrito no primeiro depoimento, a responsável pela criação avalia que a criação foi "ruim", devido às

\footnotetext{
${ }^{4}$ Fornecida para os 45 dias do ciclo de produção, criado no sistema intensivo.
} 
dificuldades enfrentadas, e ao mesmo tempo foi uma experiência boa, pelo fato do projeto de criação de ter sido implementado como um recurso não reembolsável.

\subsubsection{PRÁtiCAS PRODUTIVAS EM ESTABELECIMENTO COM BASE DE RECURSO MATERIAL COM MÉDIA DIVERSIDADE E RENDA CENTRADA NO EXTRATIVISMO DO AÇAÍ, PEIXE E CAMARÃO}

A família representativa deste tipo era constituída por 4 membros em 2012, ano da execução do projeto. $\mathrm{O}$ tamanho da área é de 13 hectares (ha) com a presença somente de área de várzea. $O$ recurso financeiro responsável pela manutenção da família se origina do subsistema extrativista representado pelo açaí, peixe e camarão. Essa estrutura interna implica na oscilação da renda ao longo do ano, atingindo baixos valores na entressafra do açaí. No caso do período do defeso, a situação financeira diverge desta realidade, já que a família possui acesso ao seguro-defeso ${ }^{5}$. Essa organização interna possibilita a reprodução social da família ao longo dos anos.

A representante desta família do tipo II acessou o projeto de forma diferenciada, em "sistema de parceria" com a esposa do cunhado. Esse sistema previa cada uma acessar um projeto diferente e ambas compartilharem os benefícios obtidos. A família do tipo II acessou o projeto de criação de frango, enquanto que a outra acessou o projeto de matapi. Assim, quando uma capturava camarão compartilhava ${ }^{6}$ com a outra e ao terminar o ciclo dos frangos, as aves foram divididas entre as duas famílias parceiras.

Ao acessar o projeto de criação de frango de granja, a família construiu a instalação para a recepção das aves, a partir dos recursos disponíveis no estabelecimento. Foram acessados 40 frangos criados de forma intensiva (presos) próximo a residência da família. Segundo a entrevistada:

Foi assim, foi de duas vezes que nós pegamos esse frango. A primeira nós cuidamos aí nós dividimos o pinteiro. Aí quando já estavam maiores a gente trocava aquela maravalha. Tinha que ter esse cuidado para eles não ficarem sujos das fezes deles. A gente trocava tudinho, ia pegar lá na cidade, vinha e trocava. Ficava todo tempo limpinho, aí a gente também trocava a água e colocava a vitamina. Umas 3 ou 4 vezes por aí, a gente colocava água. Eles comem muito, de vez em quando tem que ir lá colocar água pra eles (M. P., Ilha do Capim, 2017).

Isso revela o cuidado necessário exigido pela atividade de criação inserida no estabelecimento. Mostra também a característica de externalização (orientação externa) das práticas de manejo. Esse fenômeno fica evidente pelo uso de vitamina, a necessidade de maravalha e pelos fornecimentos de água e ração.

A alimentação fornecida às aves foi de acordo com proposta pelo projeto, seguindo as fases de crescimento, como menciona a entrevistada "era dada a inicial e a engorda, não podia dar outra coisa" (M. P., Ilha do Capim, 2017). As operações de manejo não interferiram nas demais atividades já realizadas no estabelecimento, de modo que quando o principal membro responsável pelo manejo das aves possuía necessidade de sair da casa, sua filha ficava responsável por assumir a função.

A criação de frango era realizada de forma completamente isolada de outros subsistemas, visto que não havia interações entre eles por trocas de matéria e energia. A figura

\footnotetext{
${ }^{5}$ Seguro-defeso ou seguro-desemprego do pescador artesanal (SDPA) é "uma assistência financeira temporária concedida aos pescadores profissionais artesanais que, durante o período de defeso, são obrigados a paralisar a sua atividade para preservação da espécie" (INSS, 2017).

${ }^{6}$ Cabe mencionar que este sistema permaneceu até o término do projeto, após esse período, as famílias passaram a desenvolver suas atividades de forma individual.
} 
2 deixa essa realidade evidente e mostra também a elevada dependência da instituição externa (AMIA) que promovia a incorporação dos recursos (frango e ração) para iniciar a criação e das informações baseadas em repertórios técnicos padronizados. Portanto, as práticas de manejo eram realizadas de forma distanciada da endogeneidade do estabelecimento, característica fundamental da lógica de produção agroextrativista.

Não houve problema durante a criação, mesmo não deixando luzes no ambiente à noite. A família, por não possuir energia elétrica, optou pelo não fornecimento da luz noturna à criação. Como relata a entrevistada: "De tardinha deixava bem comida lá pra eles e a água tudinho, daí só de manhã" (M. P., Ilha do Capim, 2017). A família possuía motor de luz que funciona a óleo diesel. Porém, não colocava luz no galinheiro para evitar custo com combustível.

No final do ciclo produtivo, as aves atingiram em média $3 \mathrm{~kg}$. Neste momento encontraram dificuldades de escoar a produção. Por isso, a comercialização foi realizada durante uma semana, através de mercados socialmente construídos (venda para vizinhos e por meio de jogo). Isso foi realizado através da construção de um campo de futebol e da organização de um campeonato para a venda dos frangos. Para a realização dos jogos era cobrado uma taxa de inscrição de cada time e o prêmio para os vencedores eram os frangos de granja.

A criação não avançou para outros ciclos que pudessem ser mantidos por conta própria, como prevista pelo projeto. Isso ocorreu devido à dificuldade de manter a criação a partir dos recursos gerados pela própria criação, pois a dependência completa de insumos externos dificultou a elevação das margens de renda. Além disso, a retomada da criação ficou mais difícil devido à doença que acometeu um dos filhos. Este último fator fez com que os recursos obtidos através da criação fossem utilizados pela família para a compra de remédios e para a realização de consultas médicas.

Figura 2 - Modelização do funcionamento do estabelecimento (tipo II) a partir da introdução da criação de frango.

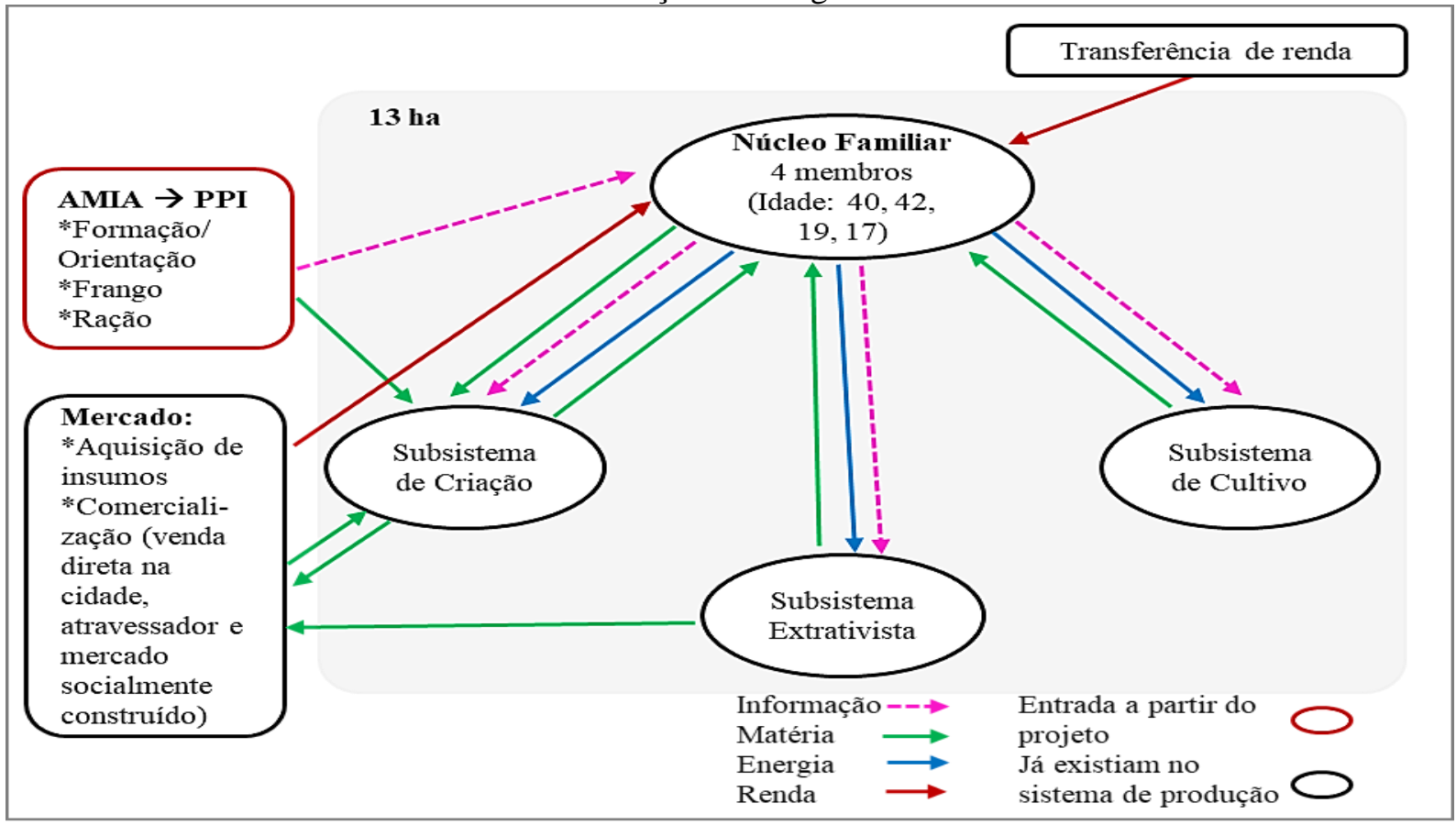

Fonte: Elaborado pelas autoras (2018).

Verifica-se também outros aspectos, como a proximidade de casas vizinhas. A entrevistada menciona que, antes da introdução da criação de frango de granja: "eu criava 
galinhas mesmo. Eu parei de criar pato e galinha, porque meus patos só dormiam na casa dos outros" (M. P., Ilha do Capim, 2017). Essa situação gerava constrangimentos com os vizinhos e implicou na eliminação do subsistema de criação animal. A família diz que criaria de novo se o projeto fosse novamente implantado na modalidade não reembolsável. Isso mostra que o principal fator que faz com que esta família acesse os projetos é o fornecimento gratuito dos recursos necessários à criação, sem os quais não é possível mantê-los no sistema de produção.

\title{
2.1.3 PRÁTICAS PRODUTIVAS EM ESTABELECIMENTO COM BASE DE RECURSO MATERIAL COM ALTA DIVERSIDADE E MÚLTIPLAS FONTES DE RENDA
}

A família representativa deste tipo possuía 2 membros no ano de 2012. O tamanho total da propriedade é de aproximadamente 182,4 ha com a presença de áreas de várzea e terra firme, localizada na Ilha do Xingu. Os recursos financeiros responsáveis pela manutenção da família são provenientes de aposentadoria, serviço público, extrativismo, cultivos e criações. Essa organização interna implica na diversidade produtiva e nas múltiplas fontes de renda que garantem a reprodução social da família agroextrativista.

Ao acessar o projeto, a família construiu uma instalação para a recepção das aves, conforme orientado pelo projeto. Para a construção utilizaram recursos locais como a palha, a madeira e o barro. A família obteve acesso a 40 frangos que foram criados de forma intensiva (preso) no aviário. Segundo o entrevistado:

Foi uma iniciativa muito boa, eu gostei. Porque graças a Deus eles me deram apoio para criar e de lá pra cá eu já não parei mais. Porque a gente se enrasca aqui...Nós aqui, quando acaba, a gente sente muito, porque quando falha a bóia [alimentação] a gente vai lá, quebra o pescoço dele, aí já safa a bóia, né (F. B., Ilha Xingu, 2017).

Isso revela que, a atividade inserida foi incorporada permanentemente pelo centro de decisão no seu sistema de produção. As práticas de manejo não interferiram nas demais atividades já realizadas no estabelecimento, já que o principal membro responsável pelo manejo das aves era a esposa que trabalha no próprio estabelecimento. Conforme menciona o entrevistado:

\begin{abstract}
De manhã cedo é só tomar café, aí eu tenho uns baldes que eu dou [alimentação] para os outros bichos [animais do subsistema de criação], eu misturo farelo com milho, faço um mingau e vou repartindo para os outros. $\mathrm{O}$ [frango] da granja eu vou pra lá, lavo as vasilhas tudinho deles, boto água, abasteço a comida e coloco a vitamina. A gente usa vitamina para os frangos da granja. A vitagold é muito boa ( $\mathrm{F}$. B., Ilha Xingu, 2017).
\end{abstract}

Diante disso, verifica-se que após a inserção da criação de frango no subsistema de criação, o manejo das diferentes espécies de aves passou a ocorrer de forma distinta: o frango de granja é criado com base em orientações externas pré-estabelecidas e as demais criações são criadas soltas com alimentações não balanceada. O fluxograma (Figura 3) a seguir demonstra de forma sintética o funcionamento do sistema família-estabelecimento.

Não houve problemas sanitários na condução das aves mencionadas pela família. Segundo eles, a principal dificuldade para a criação de frango de granja é o elevado custo com insumos. Como afirma o entrevistado "o problema mais é o preço da ração que aperreia [limita a renda] aí, mas tem que comprar" (F. B., Ilha Xingu, 2017). Esse relato demonstra a dependência de insumos externos estabelecida no sistema produtivo através da inserção da criação. Na tentativa de superar estas limitações a família forneceu às aves uma alimentação diferenciada daquela proposta pelo projeto, já que além da ração, utilizou o milho quebrado. $\mathrm{O}$ entrevistado explicou que: "eu misturo com o milho quebrado aí fica uma galinha mais 
gostosa que essa da cidade, o milho quebrado dar muito sabor na galinha, aí eu associo com a ração de engorda" (F. B., Ilha Xingu, 2017). Isso mostra que a prática foi realizada em função de duas questões principais, a redução do custo de produção (já que o milho quebrado apresenta menor custo no mercado) e a palatabilidade da carne do frango, segundo a avaliação da família.

Figura 3- Modelização do funcionamento do estabelecimento (tipo III) a partir da introdução da criação de frango.

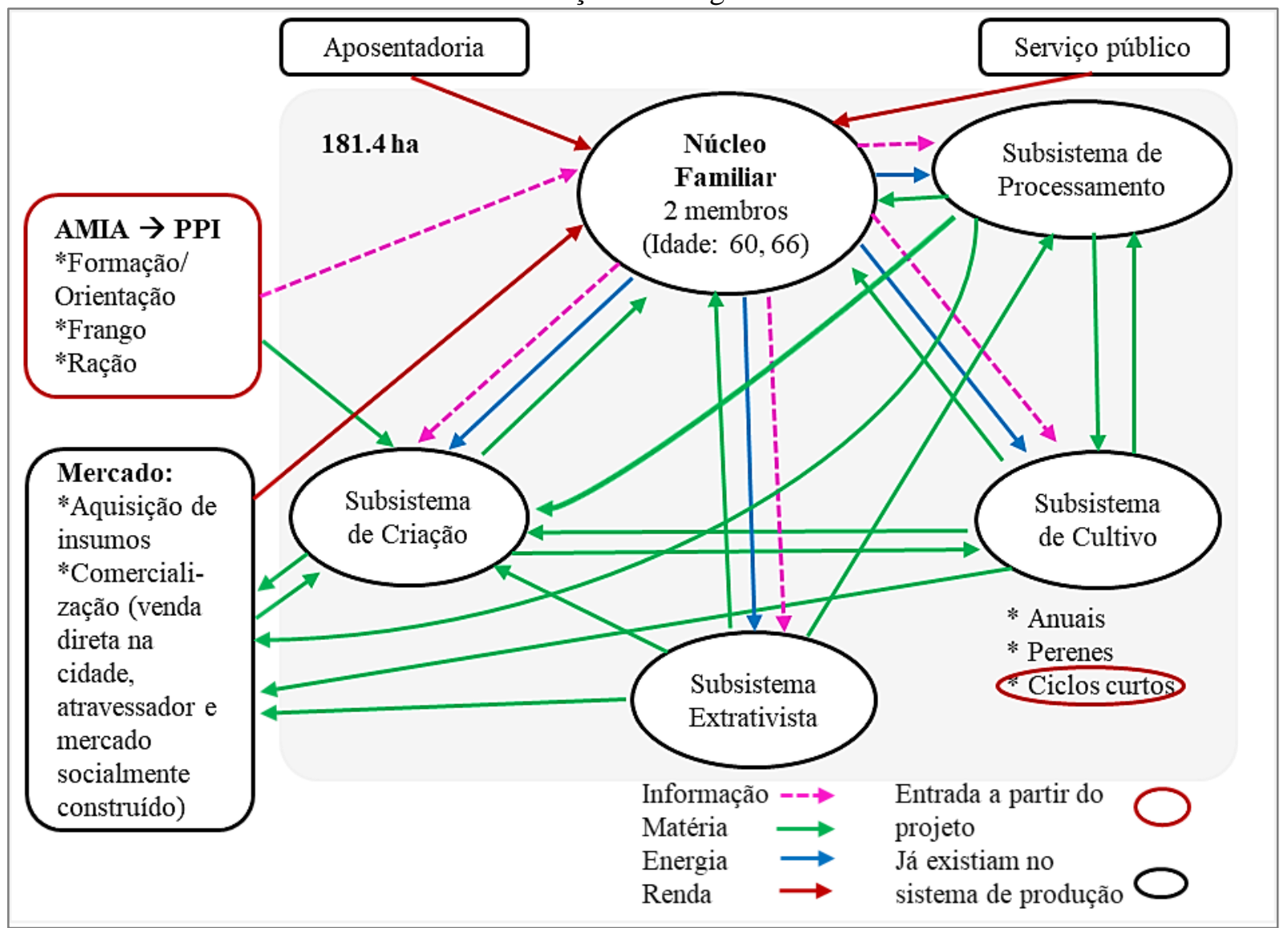

Fonte: Elaborado pelas autoras (2018).

Além da dependência de recursos externos como a ração, o enfoque programático (PETERSEN, 2011) orientador das práticas de manejo de frango de granja também representa uma dificuldade. Isso pode ser observado pelo uso da luz como prática no subsistema de criação. A família não possui acesso permanente a luz, pois a iluminação é feita com uso de um "conjugado" (motor a diesel acoplado em um gerador de luz) ligado apenas em horários específicos, das $18 \mathrm{~h}$ às $22 \mathrm{~h}$. Deste modo, a família optou por manter a iluminação do aviário somente até as $22 \mathrm{~h}$. A opção pelo horário garantiu o aumento no regime de luz e evitou a geração de um custo adicional na criação das aves.

A criação foi incorporada de forma permanente nos sistemas produtivos da família do tipo III. Quando questionado quantos lotes já retirou, o entrevistado menciona:

Olha, eu não sei de cabeça. Criei uns quantos. De lá pra cá não falhou. Só falhou agora quando nós estávamos construindo a casa [reformando o aviário]. Nós paramos porque a palha caiu tudo e a manga caiu em cima e furou tudinho. E assim mesmo, debaixo da chuva, no inverno ainda tirei uma remessa [lote], mas fica muito feio, atola, ficou muito ruim, molhou muito os pintos. Aí eu parei para reformar (F. B., Ilha Xingu, 2017). 
A experiência permanece desde o ano de 2012 e tornou-se um componente fundamental para a família a partir de ajustes nas práticas de manejo. Devido a intenção da família em permanecer com a atividade, a instalação foi reformada com materiais exógenos ao estabelecimento para aumentar a durabilidade do galinheiro.

Após a implementação da criação de frango pela AMIA, a família passou a utilizar as aves para consumo, comercialização e produção de insumos para o cultivo, principalmente de hortaliças. Este último fator representa um dos principais motivos pelo qual a família procura garantir a permanência da criação. A produção de hortaliças exige a necessidade de adubo que não está disponível em outros subsistemas do estabelecimento. Por isso, não é possível manter a produção de hortaliças sem a criação de frangos, já que estes produzem cama de aviário que é utilizado na adubação das hortaliças e dos demais cultivos. Desta forma, a criação de frango de granja permitiu o aumento da densidade conectiva dos subsistemas do estabelecimento, provocando a criação de sinergias (PETERSEN, et al., 2017), favoráveis à melhoria da renda.

A família avançou nas práticas de criação a partir da incorporação do escalonamento da produção de acordo com a demanda local de frangos. Atualmente eles possuem um galinheiro dividido em quatro áreas e inserem 25 frangos a cada 15 dias em uma destas áreas, logo após a retirada do lote anterior. A redução da quantidade total de frangos criados e o escalonamento foi realizado para evitar custos elevados na produção e garantir a regularidade na oferta de aves em condições de abate de acordo com a procura de frangos por moradores da própria localidade. Como afirma o entrevistado:

\footnotetext{
Vai ficar de 25 em 25 [frangos] para não falhar mais. Se crescer só de uma vez tem que vender logo, senão vender dá prejuízo. Aí vendendo logo os que estão maiores, os menores vão ficando e aí não vai dar prejuízo. Já é uma ideia nossa, né” (F. B., Ilha Xingu, 2017).
}

Como a comercialização é realizada localmente, não há demanda suficiente para um número elevado de aves diariamente. A venda após os 45 dias de criação ocasiona perdas significativas na renda, o que justifica a estratégia de reorganização da condução para atingir a venda de acordo com a demanda local.

Mesmo com a dependência de ração e de vitaminas que a criação de frango de granja exige, o responsável pela criação afirma: "eu não parei mais de criar e até sinto falta quando falha" (F. B., Ilha Xingu, 2017). Isso mostra que a criação passou a ser incorporada como uma estratégia de melhoria do funcionamento do estabelecimento. A dependência de insumos é uma preocupação permanente, motivo pelo qual os agricultores procuram sempre criar práticas de redução no uso de recursos externos. A criação de sinergias pelo aumento da densidade conectiva é uma prática central no subsistema de produção animal. Este fator vem sendo gradativamente aprimorado para criar novas sinergias no sistema de produção. Ao final do ciclo produtivo, aproximando aos 45 dias, os frangos chegaram a atingir $4 \mathrm{~kg}$. A partir de suas estratégias de criação e de comercialização, a família tem conseguido vender toda sua produção localmente.

\section{CONSIDERAÇÕES FINAIS}

O estudo mostrou que os agroextrativistas possuem diversidade de práticas produtivas. Essa constatação difere da compreensão dominante que entende estes atores como homogêneos. Os agricultores possuem criatividade na elaboração e implementação de suas práticas. Nem sempre os projetos de desenvolvimento pensados para melhoria das condições de vida dos agroextrativistas considera essa realidade.

O projeto de criação de frango de granja apoiou-se em um modelo agroindustrial orientado por padronizações que desconsideram a diversidade das práticas produtivas locais. 
A consequência disso foi a dificuldade de manter as criações por muito tempo, implicando no abandono destas pela maioria das famílias. A única família que conseguiu manter a criação de frango realizou um conjunto de modificações na criação padronizada, ajustando-as às especificidades de suas práticas produtivas. Isso mostra que os agricultores não são passivos, visto que recriam as atividades produtivas inseridas através de projetos e ajustam às suas formas específicas de organização e funcionamento. Nesse sentido, verifica-se a necessidade de, ao propor intervenções para realidades agroextrativistas, que seja considerada a diversidade de estratégias que permeiam as práticas produtivas das famílias, de modo que, as instituições (públicas, privadas, ONGs, organizações locais, etc.) desenvolvam projetos de desenvolvimento que sejam coerentes com as particularidades dos sistemas famíliaestabelecimento.

\section{REFERÊNCIAS}

BROSSIER, J. Système et système de production: note sur ces concepts. Cahiers des Sciences Humaines, Paris, v. 23, n. 3-4, p. 377-390, 1987. Disponível em:

https://www.documentation.ird.fr/hor/fdi:24935\#. Acesso em: 29 de ago. 2020.

CARVALHO, J. P. L.; SILVA, L. M. S. Lógicas agroextrativistas em contexto de mudanças socioeconômicas no Arquipélago do Marajó (Pará), Amazônia. Revista Brasileira de Agroecologia, v. 10, n. 1, 2015. Disponível em: http://revistas.abaagroecologia.org.br/index.php/rbagroecologia/article/view/15760/10865. Acesso em: 29 de ago. 2020.

CRUZ, M. J. M. Territorialização camponesa na várzea da Amazônia. 2007. Tese (Doutorado em Geografia Humana) - Faculdade de Filosofia, Letras, e Ciências Humanas, Universidade de São Paulo, 2007.

FALESI, I. C; SILVA, B. N. R. da; Ecossistemas de Várzeas da Região do Baixo Amazonas. Belém: Embrapa Amazônia Oriental, 1999.

FELIZARDO, A. O.; ROCHA, C. G. S. As iniciativas de desenvolvimento em comunidades agroextrativistas na Amazônia. Novos Cadernos NAEA, v. 22, n. 2, 2019. Disponível em: https://periodicos.ufpa.br/index.php/ncn/article/view/6341/5712. Acesso em: 29 de ago. 2020.

FLICK, U. Uma introdução à pesquisa qualitativa. Porto Alegre: Bookman, 2004.

GARCIA FILHO, D. P. Guia Metodológico Análise Diagnóstico de Sistemas Agrários. Brasília: INCRA/FAO, 1999.

GARCIA JÚNIOR, A. R.; HEREDIA, B. A. de. Campesinato, família e diversidade de explorações agrícolas no brasil. In: Diversidade do campesinato: expressões e categorias, v.2; Estratégias de reprodução social. Godoi, Emilia Pietrafesa de; Menezes, Marilda Aparecida de; Marin, Rosa Acevedo (orgs.). São Paulo: Editora UNESP; Brasília, DF: Núcleo de Estudos Agrários e Desenvolvimento Rural, 2009.

GODOI, E. P. DE; MENEZES, M. A. DE; MARIN, R. A. (orgs.). Diversidade do campesinato: expressões e categorias, v.2; Estratégias de reprodução social. São Paulo: Editora UNESP; Brasília, DF: Núcleo de Estudos Agrários e Desenvolvimento Rural, 2009. 
HURTIENNE, T. A agricultura familiar e o desenvolvimento sustentável: problemas conceituais e metodológicos no contexto histórico da Amazônia. Revista Econômica do Nordeste, Fortaleza, v. 30, n. Especial. p. 442 - 466, dez. de 1999. Disponível em: https://periodicos.ufpa.br/index.php/ncn/article/view/47/42. Acesso em: Acesso em: 29 de ago. 2020.

Instituto Nacional do Seguro Social - INSS. Seguro-desemprego do pescador artesanal. Disponível em: https://www.inss.gov.br/beneficios/seguro-desemprego-do-pescadorartesanal/. Acesso em: 29 de ago. de 2020.

LANDAIS E.; DEFFONTAINES, J. P. Les pratiques des agriculteurs. Point de vue sur un courant nouveau de la recherche agronomique. Études rurales. Fait partie d'un numéro thématique :Pays. Année, 1988. Volume 109. Numéro 1. p. 125-158. Disponível em : https://www.persee.fr/doc/rural_0014-2182_1988_num_109_1_3226. Acesso em : Acesso em: 29 de ago. 2020.

LANDAIS, E.; LHOSTE, P.; MILLEVILLE, P. Points de vue sur la zootechnie et sur les systèmes d'élevage tropicaux. Cahiers des Sciences Humaines, Paris, ORSTOM, v. 23, n. 34, p. 421-437, 1987.

LONG, N. E.; PLOEG, J. D. V. D. Heterogeneidade, ator e estrutura: para a reconstituição do conceito de estrutura. In: Os atores do desenvolvimento rural, perspectivas teóricas e práticas sociais. UFRGS, 2011. p. 21-48.

MARCONI, M. A; LAKATOS, E. M. Técnicas de pesquisa: planejamento e execução de pesquisas, amostragens e técnicas de pesquisas, elaboração e interpretação de dados. 3.ed. São Paulo: Atlas, 1996.

MAZOYER M. Rapport de synthèse du Comité Systèmes Agraires. Dot. provisoire. Ministère de la Recherche, 1985.

NIEDERLE, P. A. Mercantilização, estilos de agricultura e estratégias reprodutivas dos agricultores familiares de Salvador das Missões, RS. 2007. Dissertação (Mestrado em Desenvolvimento Rural) - Faculdade de Ciências Econômicas, Universidade Federal do Rio Grande do Sul, Porto Alegre, 2007.

PETERSEN, P. Metamorfosis Agroecológica: Un ensayo sobre Agroecologia Política. Maestría en Agroecología: un enfoque para la sustentabilidad rural. 2011. Dissertação (Mestrado em Agroecología un enfoque para la sustentabilidad rural) - Universidad Internacional de Andalucía, 2011.

PETERSEN, P.; DAL SOGLIO, F. K.; CAPORAL, F. R. A construção de uma Ciência a serviço do campesinato. Agricultura familiar camponesa na construção do futuro. Rio de Janeiro: AS-PTA, 2009.

PETERSEN, P; SILVEIRA, L. M da; FERNANDES, G. B; ALMEIDA, S. G de. Método de análise econômico-ecológica de Agroecossistemas. Articulação nacional de agroecologia (Brasil).- 1. Ed. - Rio de Janeiro: AS-PTA, 2017.

PINHEIRO, S. L. G. O enfoque sistêmico e o desenvolvimento rural sustentável: Uma oportunidade de mudança da abordagem hard-systems para experiências com soft-systems.

Revista Agroecologia e Desenvolvimento Sustentável, Emater, Porto Alegre, v.1, n.2, 
abr./jun. 2000, págs. 27-37. Disponível em:

http://www.geocities.ws/grupopeap/artigos/Pinheiro_2000_ADS.pdf. Acesso em: 29 de ago. de 2020.

PLOEG, J. D. V.D. Camponeses e impérios agroalimentares: lutas por autonomia e sustentabilidade na era da globalização. Tradução de Rita Pereira. Porto Alegre: UFRGS, 2008 .

RAYNAUT, C. O desenvolvimento e as lógicas da mudança: a necessidade de uma abordagem holística. Desenvolvimento e Meio Ambiente. Curitiba: Editora UFPR, n. 1, p.81-104, 1994.

REIJNTJES, C.; HAVERKORT, B.; WATERS-BAYER, A. Agricultura para o futuro: uma introdução a agricultura sustentável e de baixo uso de insumos externos. Trad. John Cunha Comerford. 2. ed. Rio de Janeiro: AS-PTA: Leusden Holanda: ILEIA, 1999. 